\title{
Activation of caspases and apoptosis in response to low-voltage electric pulses
}

\author{
NORIAKI MATSUKI ${ }^{1}$, MOTOHIRO TAKEDA $^{3}$, TAKUJI ISHIKAWA ${ }^{2}$, AKI KINJO $^{4}$, \\ TOMOAKI HAYASAKA ${ }^{2}$, YOHSUKE IMAI ${ }^{2}$ and TAKAMI YAMAGUCHI ${ }^{1,2}$ \\ ${ }^{1}$ Department of Biomedical Engineering, Graduate School of Biomedical Engineering; \\ ${ }^{2}$ Department of Bioengineering and Robotics, Graduate School of Engineering, Tohoku University, 6-6-01, \\ Aoba, Aramaki, Aoba-ku, 980-8579 Sendai; ${ }^{3}$ Division of Nano-Medical Science, Graduate School of Medicine, \\ Tohoku University, 1-1, Seiryo-machi, Aoba-ku, 980-8574 Sendai; ${ }^{4}$ Department of Oral Maxillofacial Surgery, \\ Graduate School of Dentistry, Kyushu University, 3-1-1, Maidashi, Higashi-ku, 812-8592 Fukuoka, Japan
}

Received November 26, 2009; Accepted January 14, 2010

DOI: 10.3892/or_00000780

\begin{abstract}
Few studies have examined apoptosis induced by low-voltage electric pulses (LVEPs). LVEP-induce changes in membrane potential that are below the membrane breakdown threshold and increase membrane permeability without electroporation (pore formation) through the transport of extracellular substances via phagocytosis. We demonstrated that propidium iodide uptake and apoptosis increased in accordance with the duration and number of LVEPs in B16 cells, which showed relatively good viability under mild electric field conditions. We showed that LVEP-induced apoptosis was achieved through caspase- 8 and -9 activation and subsequent caspase-3 activation. Long-duration LVEPs caused only mild cell damage, such that the apoptosis ratio (apoptosis/total cell death) in electric pulse-treated cells was similar to that in non-treated control cells. To assess the relative degree of caspase dependency in LVEP-induced apoptosis, the apoptosis rate and caspase-3 activity were analyzed using a pan-caspase inhibitor (Z-VAD-FMK). Z-VAD-FMK treatment inhibited, but did not abolish, LVEP-induced apoptosis, indicating that caspases other than caspase-3 participate in this pathway. Moreover, LVEP treatment inhibited cell growth, suggesting that LVEP treatment may be a valuable anticancer therapy. Although the mechanism of LVEP-induced apoptosis remains unclear, it may be related to dysfunctional membrane transport of $\mathrm{Ca}^{2+}$ and other extracellular substances involved in caspase activation.
\end{abstract}

Correspondence to: Dr Noriaki Matsuki, Department of Bioengineering and Robotics, Tohoku University, 6-6-01, Aoba, Aramaki, Aoba-ku, 980-8579 Sendai, Japan

E-mail: matsuki@pfsl.mech.tohoku.ac.jp

Key words: apoptosis, caspase-3, low-voltage electric pulse, membrane permeability, Z-VAD-FMK

\section{Introduction}

Electric fields have been widely used in a variety of in vitro and in vivo biotechnical applications (1-3). Electroporation, in particular, has been investigated as a novel anticancer therapy, known as electrochemotherapy (3). The applied electric field generates large depolarizing and hyperpolarizing transmembrane potentials across the cell, followed by electrical membrane breakdown when the membrane potential reaches a critical value (i.e., the membrane breakdown threshold), resulting in the formation of pores. During the effective 'pore open time', solutes that are typically unable to permeate the membrane are added to the extracellular medium and allowed to enter the cell via the pores $(1,4)$. This method has been used to introduce anticancer agents that effectively induce cancer cell death (3).

However, the application of high-intensity electric fields also induces necrotic cell death, rather than apoptosis, as a result of cell damage (5-7). Necrotic cells are characterized by irreversible plasma membrane rupture as a result of severe cell damage and dysfunction, which in turn induces an inflammatory reaction. In contrast, the membrane integrity of an apoptotic cell is maintained and the cell is removed by phagocytosis without inducing an inflammatory response $(8,9)$. Thus, developing methods to selectively induce apoptosis, rather than necrosis, is a desirable endpoint for anticancer therapy (10). However, high-intensity electric fields may also cause undesirable side effects (6). Therefore, apoptosis induced by a milder electric field would be a favorable alternative to high-voltage electroporation.

Previous studies reported that a moderate electric field induced apoptosis (11). Furthermore, we previously demonstrated that a relatively low-intensity electric field, with a membrane potential approximately half that of the membrane breakdown threshold of mammalian cells, induced a higher apoptosis ratio (apoptosis/necrosis) than high-intensity electric fields in human squamous cell carcinoma of the tongue (SCC 9) cells (12). In general, mild electric fields appear to induce less cell damage and greater cell survival than highintensity fields. If the transmembrane potential induced by such 
a field is lower than the membrane breakdown threshold, membrane permeability increases without pore formation (electroporation). However, the detailed mechanism underlying mild electric field-induced permeability is unclear, although some studies have indicated that endocytosis and structural deformation of the cell membrane may be involved $(13,14)$. Moreover, mild electric fields enhance the anticancer immune system $(15,16)$. Therefore, research into the cellular effects of exposure to mild electric fields is useful for cancer research.

To date, very few studies exist regarding apoptosis in cancer cells under mild electric fields. Therefore, we investigated the relationship between pulse duration and apoptosis under mild electric fields using low-voltage electric pulses (LVEPs) and we examined the role of caspase pathways in the subsequent cellular response.

\section{Materials and methods}

Cell culture. The B16 (mouse malignant melanoma) cell line was obtained from the Cell Resource Center for Biomedical Research at the Institute of Development, Aging and Cancer of Tohoku University. Cells were cultured in RPMI-1640 medium (Irvine Scientific, Santa Ana, CA, USA) containing $10 \%$ heat-inactivated fetal bovine serum (FBS; Gibco, Grand Island, NY, USA), $50 \mathrm{U} / \mathrm{ml}$ penicillin (Gibco) and $50 \mu \mathrm{g} / \mathrm{ml}$ streptomycin (Gibco) at $37^{\circ} \mathrm{C}$ in a humidified chamber under $5 \% \mathrm{CO}_{2} / 95 \%$ air.

Exposure to LVEPs. Cells were collected after trypsinization, centrifuged for $5 \mathrm{~min}$ at $300 \mathrm{x} \mathrm{g}$, washed in phosphate-buffered saline (PBS) and re-suspended in PBS or RPMI-1640 at a concentration of $2-3 \times 10^{6}$ cells $/ \mathrm{ml}$. The cell suspensions (400 $\mu \mathrm{l}$ ) were transferred to parallel aluminum-plated electroporation/fusion chambers with 2-mm gaps (Bio-Rad, Hercules, CA, USA). Relatively low-voltage, long-duration $(7.5 \mathrm{~V} / \mathrm{mm}$, 100-2000 ms) square wave consecutive pulses (1-3 pulses; duty ratio $=0.5)$ were applied using a function generator (FG-273; Kenwood, Tokyo, Japan).

Evaluation of membrane permeability. Membrane permeability was assessed by staining with $5 \mu \mathrm{l}$ of propidium iodide (PI; Cell Technology, Inc., Mountain View, CA, USA) in $400 \mu 1$ of cell suspension, followed by flow cytometry. Cells were washed, re-suspended at a concentration of $2-3 \times 10^{6}$ cells $/ \mathrm{ml}$ in PBS and stained with $5 \mu 1$ of PI in $400 \mu 1$ of cell suspension. Following exposure to LVEPs, the cells were immediately analyzed by flow cytometry according to the manufacturer's protocol.

Viability assay. For the viability analysis, the cells were washed and re-suspended in RPMI-1640 at a concentration of 2-3×106 cells $/ \mathrm{ml}$. They were placed on ice for $3 \mathrm{~min}$ and then subjected to LVEP exposure. They were then immediately placed on ice for $30 \mathrm{~min}$ and analyzed using a cell viability analyzer (Vi-Cell XR; Beckman Coulter, Fullerton, CA, USA).

Apoptosis assay. A flow cytometry apoptosis detection kit (Annexin V-FITC/7-AAD kit; Beckman Coulter) was used to identify apoptotic and necrotic cells according to the manufacturer's protocol. Briefly, cells $\left(2-3 \times 10^{6}\right.$ cells $\left./ \mathrm{ml}\right)$ were double-stained with $10 \mu 1$ of fluorescein isothiocyanate (FITC)-labeled annexin V to detect phosphatidylserine expression during early apoptotic phases and $10 \mu \mathrm{l}$ of 7-AAD to exclude late apoptotic and necrotic cells. Samples were analyzed using a desktop cell sorter (JSAN; Bay Bioscience, Kobe, Japan). The number of positive cells was determined in the annexin-positive fraction of the cell suspension by an arbitrary threshold setting allowing not $>5 \%$ positive counts in the negative control. Cells positive for annexin alone were defined as apoptotic, whereas those positive for both annexin and 7-AAD were defined as necrotic/late apoptotic.

Caspase activity. Caspase-3 activity was measured using a caspase- 3 activity detection kit (APO LOGIX ${ }^{\mathrm{TM}}$ Carboxyfluorescein Caspase Detection Kit, FAM-DEVD-FMK for caspase-3 detection; Cell Technology, Inc., Mountain View, CA, USA) according to the manufacturer's protocol. Briefly, cells were plated in a 24 -well plate at a concentration of $1 \times 10^{6}$ cells $/ \mathrm{ml}$; each well contained $300 \mu 1$ of RPMI-1640 supplemented with $10 \%$ FBS. After LVEP treatment, the cells were incubated in $300 \mu 1$ of PBS containing $10 \mu 1$ of caspase substrate (FAM-DEVD-FMK) for $1 \mathrm{~h}$ at $37^{\circ} \mathrm{C}$ under $5 \% \mathrm{CO}_{2} / 5 \%$ air. The cells were then collected and washed in washing buffer and FITC fluorescence was measured by flow cytometry.

The activation of caspase- 8 and -9 was determined in the same manner using a caspase- 8 or -9 activity detection kit (APO LOGIX Carboxyfluorescein Caspase Detection Kit, FAM-LETD-FMK for caspase-8 detection, FAM-LEHD-FMK for caspase-9 detection; Cell Technology, Inc.).

Pan-caspase inhibition. N-benzyloxycarbonyl-Val-Ala-Aspfluoromethylketone (Z-VAD-FMK; Calbiochem, San Diego, CA, USA) is a membrane permeable, irreversible inhibitor of caspase-1, $-3,-4$ and -7 . Briefly, cells were incubated at a final concentration of $100 \mu \mathrm{M} \mathrm{Z-VAD-FMK}$ for $1 \mathrm{~h}$ at $37^{\circ} \mathrm{C}$ under $5 \% \mathrm{CO}_{2} / 95 \%$ air before LVEP application. The cells were then exposed to electric pulses, and subjected to flow cytometry to evaluate apoptosis and caspase- 3 activity.

Cell growth. B16 cell growth was evaluated by cell counting. Briefly, cells were exposed to triple square wave pulses at $15 \mathrm{~V}(7.5 \mathrm{~V} / \mathrm{mm})$ for $1000 \mathrm{~ms}$. The electric pulse-treated cells and control cells in each sample $\left(5 \times 10^{4}\right.$ cells $)$ were then plated into 6-well plates containing RPMI-1640 supplemented with $10 \% \mathrm{FBS}$ and incubated at $37^{\circ} \mathrm{C}$ under $5 \% \mathrm{CO}_{2} / 95 \%$ air. During incubation, cell number was determined using a cell viability analyzer (Vi-Cell XR; Beckman Coulter) every $24 \mathrm{~h}$ for 6 days.

Statistical analysis. Statistical analysis was performed using StatView 5.0 software (SAS Institute Inc., Cary, NC, USA). Comparisons of means were conducted by analysis of variance (ANOVA) and a post hoc test (Fisher's PLSD); $\mathrm{P}<0.05$ was considered significant.

\section{Results}

Evaluation of membrane permeability. To determine the relationship between membrane permeability and the pulse 


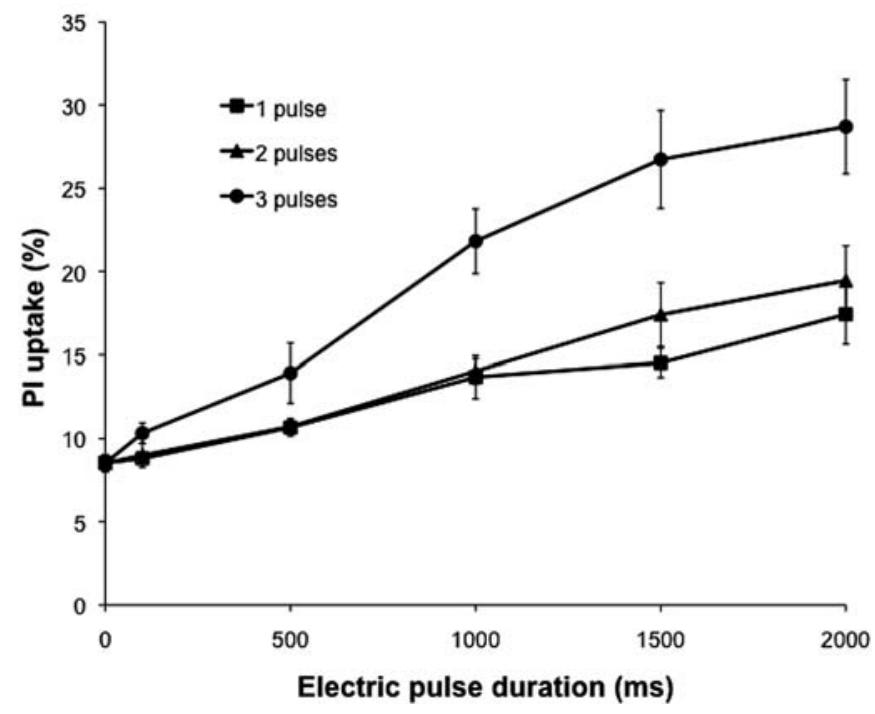

Figure 1. Propidium iodide (PI) uptake in B16 cells after the application of low-voltage electric pulses. Cells cultured in the presence of PI were exposed to single, double, or triple electric pulses of varying durations and analyzed using flow cytometry. Square, single electric pulse; triangle, double electric pulse; circle, triple electric pulse. Data are shown as the mean \pm standard error of the mean of three separate experiments, each performed in duplicate.

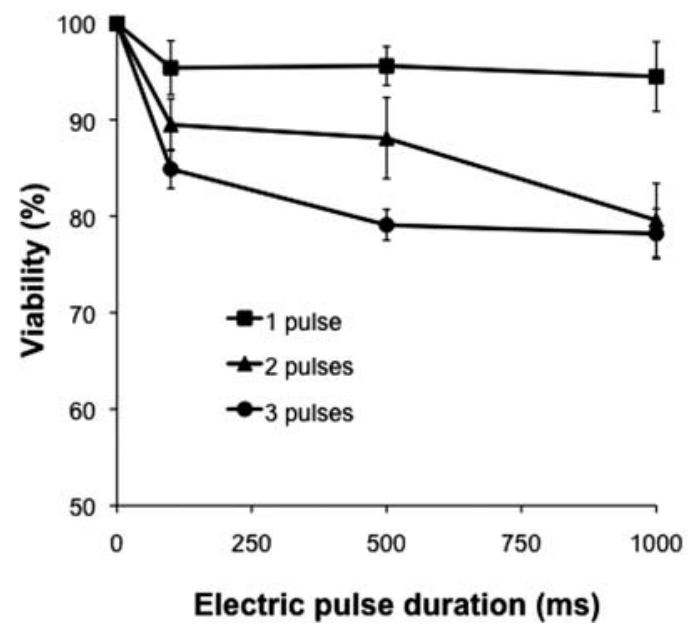

Figure 2. Cell viability after the application of triple electric pulses of varying durations. Cells were exposed to three relatively low-voltage electric pulses $(15 \mathrm{~V} / 2 \mathrm{~mm})$ of varying durations. Viability was analyzed using a cell viability analyzer $30 \mathrm{~min}$ after the administration of the electric pulses. Data are shown as the mean \pm standard error of the mean of three separate experiments, each performed in duplicate.

duration in low-voltage electric fields, cells in PBS containing PI were exposed to a $15-\mathrm{V}(7.5 \mathrm{~V} / \mathrm{mm})$ square wave; after exposure to single, double, or triple electric pulses of various durations, the cells were analyzed by flow cytometry (Fig. 1).

After a single pulse for 0 (control), 100, 500, 1000, 1500, or $2000 \mathrm{~ms}$, the cells exhibited PI uptake values of $8.5 \pm 0.5$, $9.0 \pm 0.3,10.7 \pm 0.5,13.7 \pm 1.3,14.5 \pm 0.9$ and $17.4 \pm 1.8 \%$, respectively. After a double pulse, the cells exhibited respective PI uptake values of $8.5 \pm 0.5,9.0 \pm 0.7,10.7 \pm 0.4,14.0 \pm 0.7$, $17.4 \pm 1.9$ and $19.5 \pm 2.1 \%$. After a triple pulse, the cells exhibited PI uptake values of $8.5 \pm 0.5,10 . \pm 0.3,13.9 \pm 1.8$,
$21.8 \pm 1.9,26.7 \pm 2.9$ and $28.7 \pm 2.8 \%$, respectively. These results indicated that membrane permeability increases in accordance with pulse duration and electric pulse number in B16 cells. Although single and double pulses induced only small differences in membrane permeability, triple pulses elicited large increases in membrane permeability. However, severe bubble formation or cell aggregation were noted after 1500and 2000-ms pulses in the double and triple electric pulse treatments; for this reason, all subsequent experiments were performed using a pulse duration of $<1000 \mathrm{~ms}$.

Viability. To assess cell damage due to electric pulses, cell viability was examined. Cells were stained with trypan blue for $30 \mathrm{~min}$ after the application of a $15-\mathrm{V}(7.5 \mathrm{~V} / \mathrm{mm})$ square wave, again examining single, double, and triple electric pulses of varying durations. The cell viability analysis revealed that $95.9 \pm 1.0 \%$ of control cells were viable. This value was set as $100 \%$ viability and all experimental groups were compared against this value. After a single electric pulse at 100,500 , or $1000 \mathrm{~ms}, 95.4 \pm 2.7,95.6 \pm 2.0$ and $94.5 \pm 3.6 \%$ of cells, respectively, were viable. After a double electric pulse at 100 , 500 , or $1000 \mathrm{~ms}, 89.5 \pm 2.7,88.1 \pm 4.2$, and $79.6 \pm 3.8 \%$ of cells, respectively, were viable. After a triple electric pulse at 100 , 500 , or $1000 \mathrm{~ms}, 84.9 \pm 2.0,79.1 \pm 1.6$ and $78.2 \pm 2.6 \%$ of cells, respectively, were viable (Fig. 2). These results indicated that increasing pulse number and duration cause cell damage. Notably, very little difference in cell viability was observed after triple electric pulses of 500 and $1000 \mathrm{~ms}$.

Induction of apoptosis and cell death. To determine the relationship between apoptosis and the duration of LVEPs, cells were exposed to triple $15-\mathrm{V}(7.5 \mathrm{~V} / \mathrm{mm})$ square waves of varying durations and then analyzed via flow cytometry $24 \mathrm{~h}$ later. As a positive control for apoptotic induction, we also examined cells treated with cisplatin $(10.0 \mu \mathrm{g} / \mathrm{ml})$ for $24 \mathrm{~h}$ $(17,18)$.

Fig. 3A shows flow cytometric plots for annexin V-FITC and 7-AAD staining. Cell populations exposed to electric pulses shifted to the right and upward compared to control cells, similar to cells incubated with cisplatin. These results indicated that electric pulses induce apoptosis as well as necrosis.

The rates of apoptotic cell death are shown in Fig. 3B. On average, apoptosis occurred in $2.8 \pm 0.3 \%$ of the control cells ( $\mathrm{P}<0.01$ vs. $500 \mathrm{~ms}, 1000 \mathrm{~ms}$ and cisplatin), $3.2 \pm 0.7 \%$ of cells exposed to $100-\mathrm{ms}$ triple pulses $(\mathrm{P}<0.05$ vs. $500 \mathrm{~ms}$ and cisplatin, $\mathrm{P}<0.01$ vs. $1000 \mathrm{~ms}), 7.2 \pm 0.5 \%$ of cells exposed to 500-ms triple pulses ( $\mathrm{P}<0.05$ vs. control, $100 \mathrm{~ms}$ and $1000 \mathrm{~ms})$, $10.5 \pm 1.6 \%$ of cells exposed to $1000-\mathrm{ms}$ pulses $(\mathrm{P}<0.05$ vs. $500 \mathrm{~ms}$ and cisplatin, $\mathrm{P}<0.01 \mathrm{vs}$. control and $100 \mathrm{~ms})$ and $7.4 \pm 0.4 \%$ of the cisplatin-treated cells $(\mathrm{P}<0.05 \mathrm{vs} .100 \mathrm{~ms}$ and $1000 \mathrm{~ms}, \mathrm{P}<0.01$ vs. control).

Fig. 3C shows the rate of necrosis in cells exposed to electric pulses. Generally, necrosis and late apoptosis are difficult to distinguish. Both involve membrane breakdown and result in inflammatory reactions; for these reasons, late apoptosis was grouped with necrosis in this study. On average, cell death occurred in $7.5 \pm 0.8 \%$ of the control cells $(\mathrm{P}<0.01$ vs. 500 and $1000 \mathrm{~ms}), 9.7 \pm 1.2 \%$ of the cells exposed to $100-\mathrm{ms}$ pulses $(\mathrm{P}<0.01$ vs. 500 and $1000 \mathrm{~ms}), 19.0 \pm 2.1 \%$ of the cells 
A
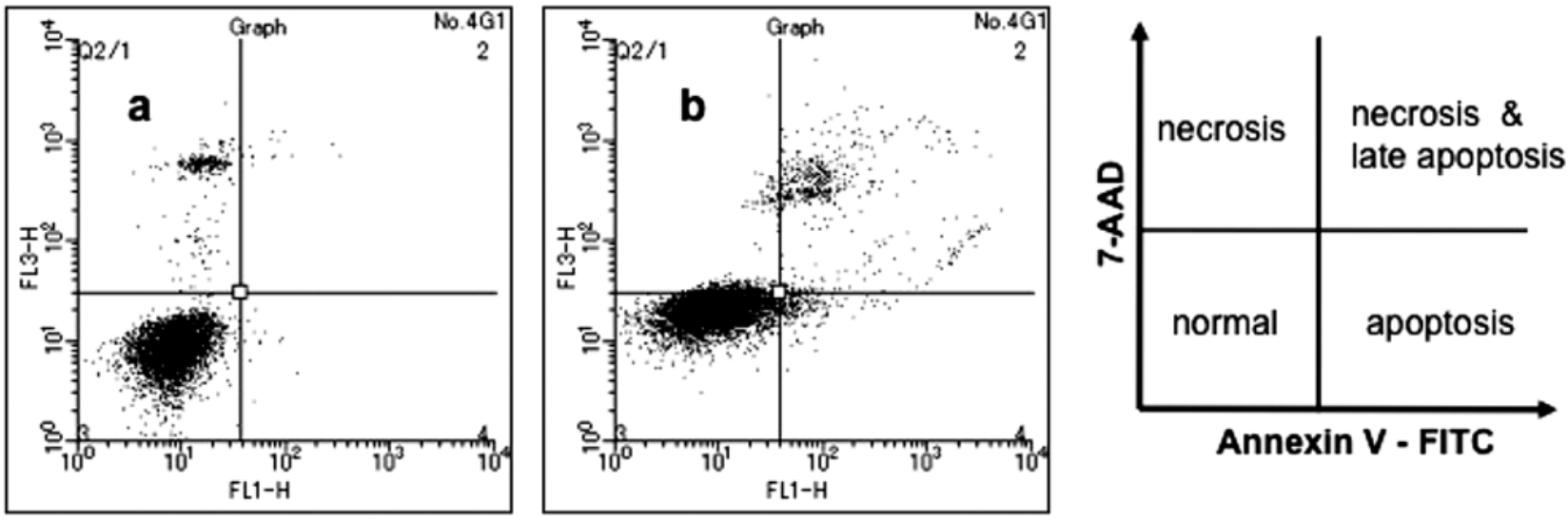

Annexin V - FITC
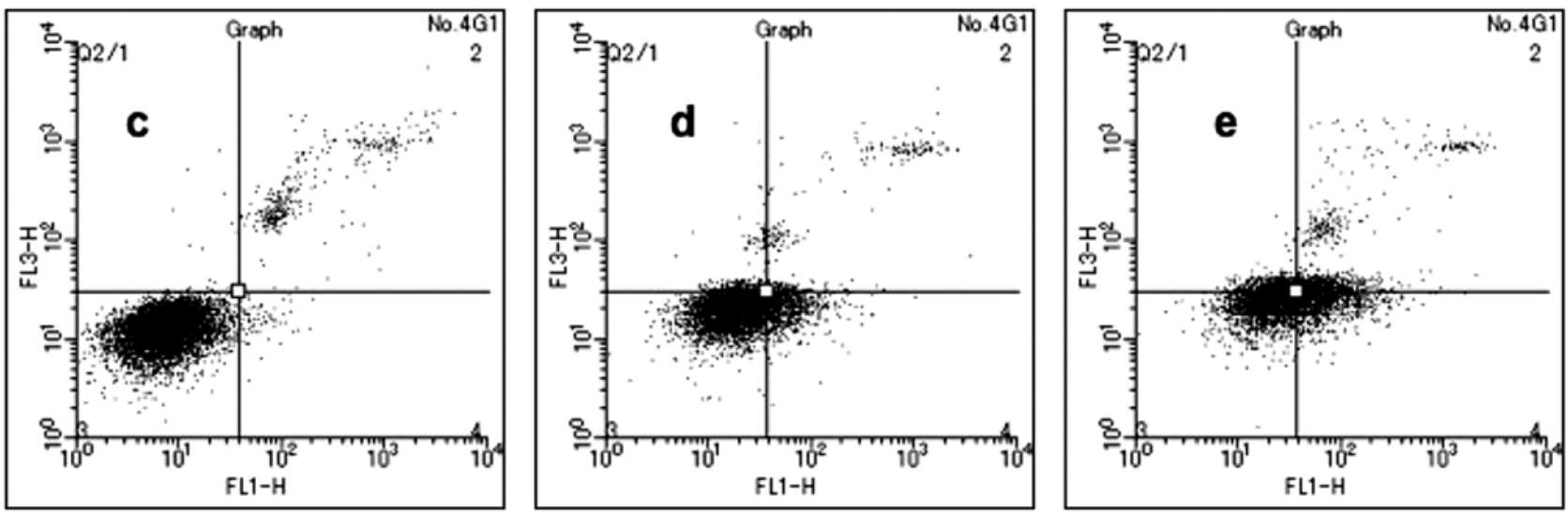

B

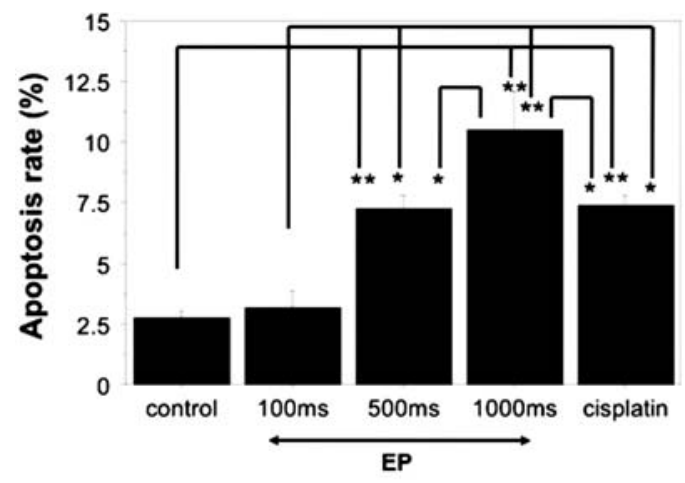

Electric pulse duration (ms) / cisplatin
C

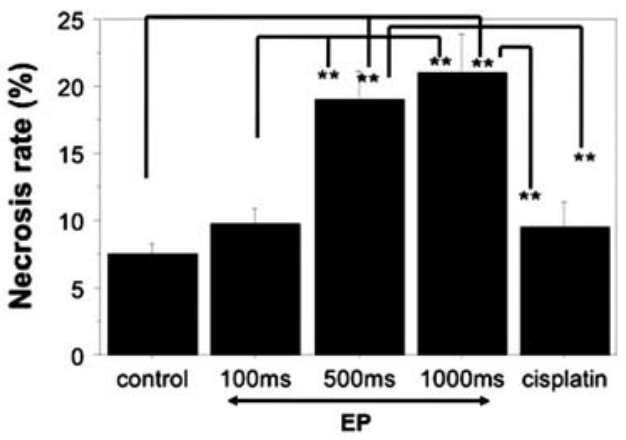

Electric pulse duration (ms) / cisplatin

Figure 3. Induction of apoptosis and cell death following the administration of electric pulses. Cells were exposed to three relatively low-voltage electric pulses $(15 \mathrm{~V} / 2 \mathrm{~mm})$ of varying durations and analyzed via flow cytometry with annexin V-FITC and 7-AAD staining $24 \mathrm{~h}$ later. Cells treated with cisplatin $(10.0 \mu \mathrm{g} / \mathrm{ml})$ for $24 \mathrm{~h}$ were used as positive controls for apoptosis. (A) Flow cytometry plot for annexin V-FITC and 7-AAD staining. Annexin V (-) and 7-AAD (-) cells were considered intact; annexin (+) and 7-AAD (-) cells were considered apoptotic; 7-AAD (+) cells were considered necrotic. (a) Control cells; (b) cisplatin-treated cells; (c) 100-ms electric pulse; (d) 500-ms electric pulse; (e) 1000-ms electric pulse. (B) Apoptosis rate. (C) Necrosis rate. (D) Apoptosis/total cell death ratio. Data are shown as the mean \pm the standard error of the mean of four separate experiments. ${ }^{*} \mathrm{P}<0.05$; ${ }^{* *} \mathrm{P}<0.01$. 
A

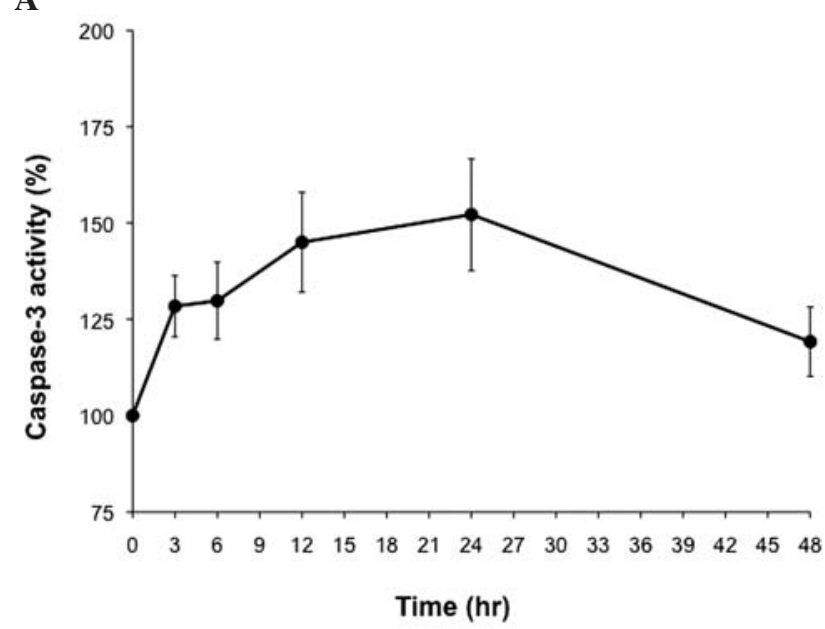

B

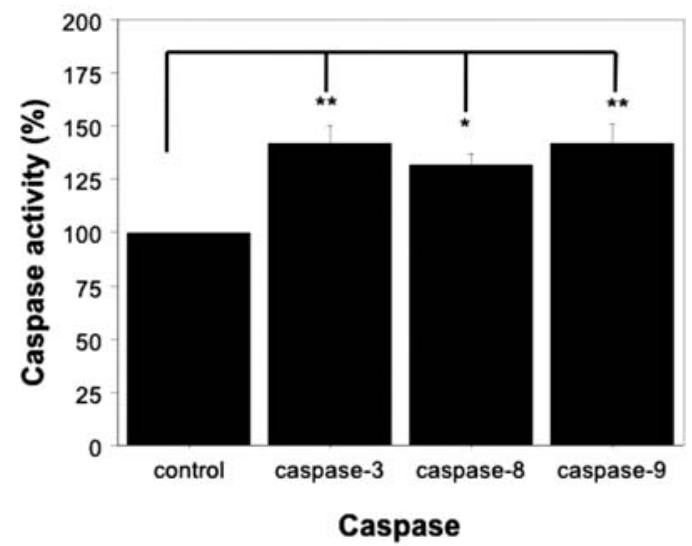

Figure 4. Caspase activation. (A) Caspase-3 activity over time after the administration of electric pulses. Caspase-3 activity was measured using flow cytometry at $3,6,12,24,48 \mathrm{~h}$ after the application of triple electric pulses $(15 \mathrm{~V} / 2 \mathrm{~mm}, 1000 \mathrm{~ms}$ in duration). Data are shown as the mean $\%$-fluorescence intensity (FI) relative to the control \pm the standard error of the mean of three separate experiments, each performed in duplicate. (B) Caspase- 3 , -8 , and -9 activities $12 \mathrm{~h}$ after the administration of electric pulses. Data are shown as the mean $\%$-FI relative to the control \pm the standard error of the mean of three separate experiments, each performed in duplicate. ${ }^{*} \mathrm{P}<0.05 ;{ }^{* *} \mathrm{P}<0.01$.

exposed to $500-\mathrm{ms}$ pulses $(\mathrm{P}<0.01$ vs. control, $100 \mathrm{~ms}$ and cisplatin), $21.0 \pm 2.9 \%$ of the cells exposed to 1000 -ms pulses $(\mathrm{P}<0.01$ vs. control, $100 \mathrm{~ms}$, and cisplatin) and $9.5 \pm 1.9 \%$ of cisplatin-treated cells ( $\mathrm{P}<0.01$ vs. $500 \mathrm{~ms}$ and $1000 \mathrm{~ms}$ ).

Fig. 3D shows the ratio of apoptosis/total cell death in cells exposed to electric pulses. On average, apoptosis accounted for $25.1 \pm 1.6 \%$ of total cell death in control cells ( $\mathrm{P}<0.05$ vs. $1000 \mathrm{~ms}, \mathrm{P}<0.01$ vs. cisplatin), $25.2 \pm 3.2 \%$ of total cell death in cells exposed to $100-\mathrm{ms}$ pulses ( $\mathrm{P}<0.01$ vs. cisplatin), $26.1 \pm 1.9 \%$ of total cell death in cells exposed to $500-\mathrm{ms}$ pulses ( $\mathrm{P}<0.01$ vs. cisplatin), $31.7 \pm 1.8 \%$ of total cell death in cells exposed to $1000-\mathrm{ms}$ pulses $(\mathrm{P}<0.05$ vs. control), and $39.9 \pm 3.4 \%$ of total cell death in cisplatin-treated cells $(\mathrm{P}<0.01$ vs. control, $100 \mathrm{~ms}$ and $500 \mathrm{~ms}$ ). Together, these data indicated that longer duration pulses induce significant cell damage, leading to necrosis as well as apoptosis. However, longer duration pulses resulted in fewer damaged (necrotic) cells while still inducing apoptosis.

Caspase-3 activity. To determine whether caspase pathways are involved in LVEP-induced apoptosis, cells were exposed to triple square wave pulses at $15 \mathrm{~V}(7.5 \mathrm{~V} / \mathrm{mm})$ for $1000 \mathrm{~ms}$. Following electric pulse treatment, caspase-3 activity was measured over time (at 3, 6, 12, 24 and 48 h) using flow cytometry.

Fig. 4A illustrates caspase-3 activation over time. The fluorescence intensity of the control cells was regarded as $100 \%$ activation. On average, the relative \%-fluorescence intensity of the cells exposed to electric pulses increased $128.4 \pm 7.9 \%$ relative to that of the control cells at $3 \mathrm{~h}$, $129.8 \pm 10.0 \%$ at $6 \mathrm{~h}, 145.0 \pm 13.0 \%$ at $12 \mathrm{~h}, 152.2 \pm 14.5 \%$ at $24 \mathrm{~h}$ and $119.2 \pm 9.0 \%$ at $48 \mathrm{~h}$. Caspase- 3 activation increased within $3 \mathrm{~h}$ after electric pulse exposure and increased gradually until $24 \mathrm{~h}$. Thereafter, caspase- 3 activation decreased gradually, but did not recover to the control level at $48 \mathrm{~h}$. These results indicated that caspase- 3 activity persisted after LVEP stimulation and that caspase pathways likely play a major role in LVEP-induced apoptosis.

Caspase-8 and -9 activation. To elucidate the apoptotic pathway activated by LVEP stimulation, caspase- 8 and -9 activities were measured $12 \mathrm{~h}$ after the application of triple square wave electric pulses at $15 \mathrm{~V}(7.5 \mathrm{~V} / \mathrm{mm})$ for $1000 \mathrm{~ms}$. Caspase- 8 and -9 are known as initiator caspases that activate the cell death receptor and mitochondrial apoptotic pathways, respectively. Fig. 4B shows the changes in caspase-3, -8 , and -9 activities relative to the fluorescence intensity of the control cells (set at 100\%). On average, the relative \%-fluorescence intensity of cells exposed to electric pulses increased $142.0 \pm 8.3 \%$ for caspase- 3 ( $\mathrm{P}<0.01$ vs. control), $131.4 \pm 5.8 \%$ for caspase- $8(\mathrm{P}<0.05$ vs. control) and $141.5 \pm 9.4 \%$ for caspase-9 $(\mathrm{P}<0.01$ vs. control). These results indicated that LVEPs activate both caspase- 8 and -9 (i.e., both the cell death receptor and mitochondrial pathways).

Effects of pan-caspase inhibition on apoptosis and caspase-3 activity. To assess the relative degree of caspase dependency in LVEP-induced apoptosis, cells were incubated with the pan-caspase inhibitor Z-VAD-FMK for $1 \mathrm{~h}$ before exposure to a triple square wave electric pulse at $15 \mathrm{~V}(7.5 \mathrm{~V} / \mathrm{mm})$ for $1000 \mathrm{~ms}$. Then, apoptosis and caspase-3 activity were analyzed using flow cytometry at $24 \mathrm{~h}$. Fig. 5A shows the flow cytometric plots for annexin V-FITC and 7-AAD staining; these data show that Z-VAD-FMK inhibits LVEP-induced apoptosis.

Fig. 5B shows the rate of apoptosis in LVEP-exposed cells. On average, apoptosis occurred in $2.3 \pm 0.6 \%$ of the control cells $(\mathrm{P}<0.01 \mathrm{vs}$. electric pulse $), 3.8 \pm 1.4 \%$ of the cells incubated with Z-VAD-FMK ( $\mathrm{P}<0.01$ vs. electric pulse), $9.1 \pm 1.0 \%$ of the cells exposed to electric pulses $(\mathrm{P}<0.01 \mathrm{vs}$. control and Z-VAD-FMK, $\mathrm{P}<0.05$ vs. electric pulse $+\mathrm{Z}$ VAD-FMK), $5.2 \pm 1.3 \%$ of the cells exposed to electric pulses 
A
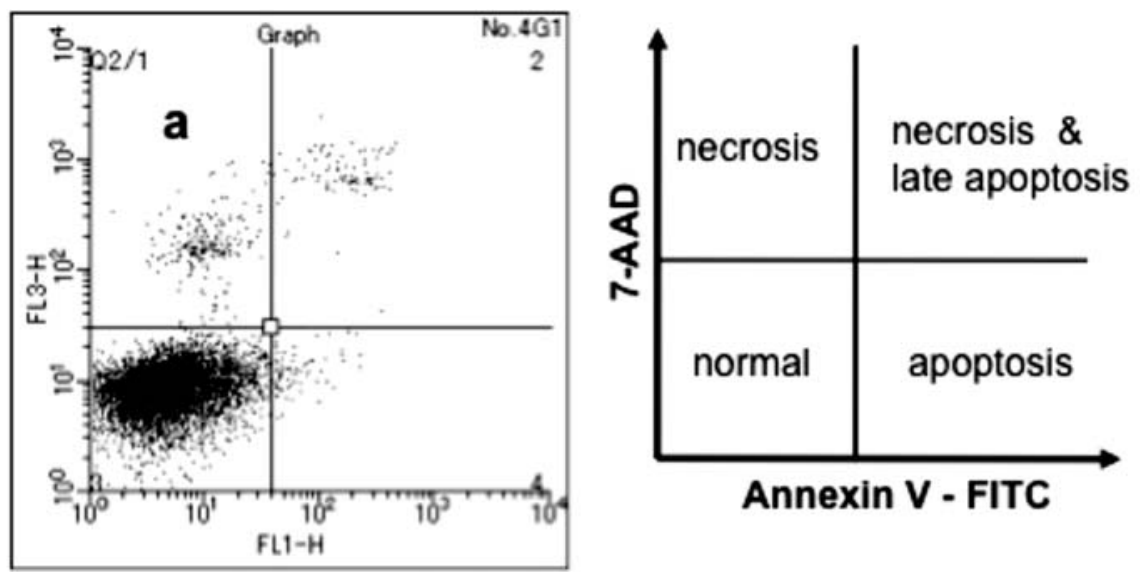

Annexin V - FITC
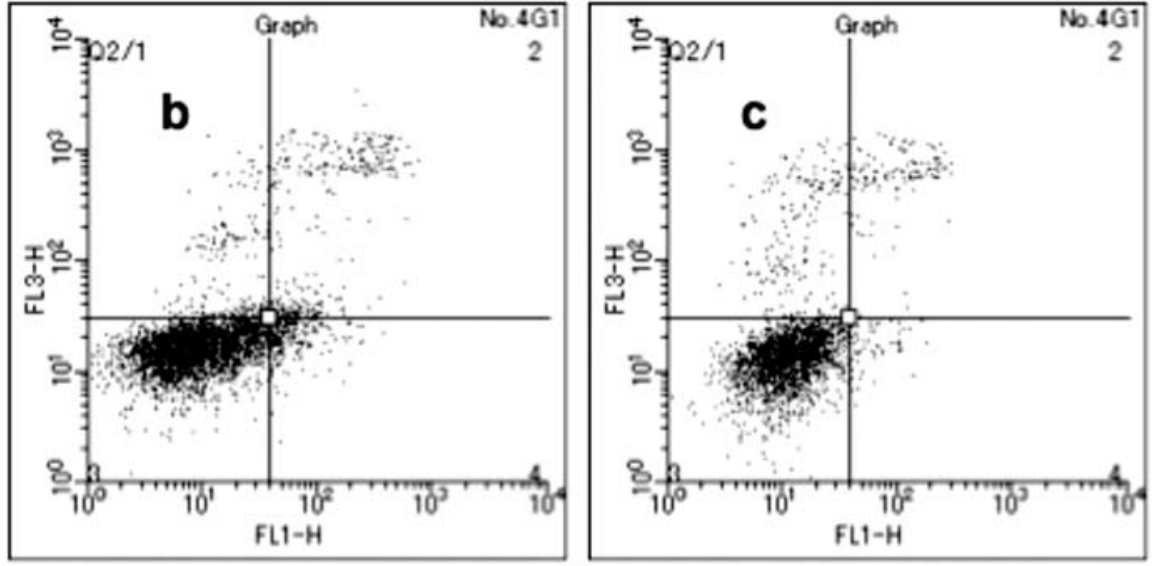

B

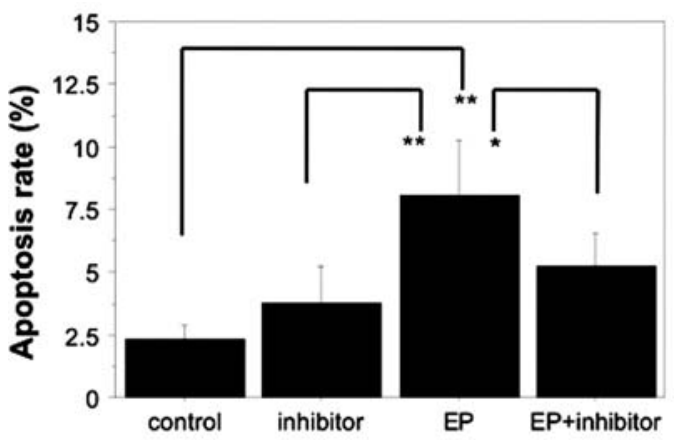

C

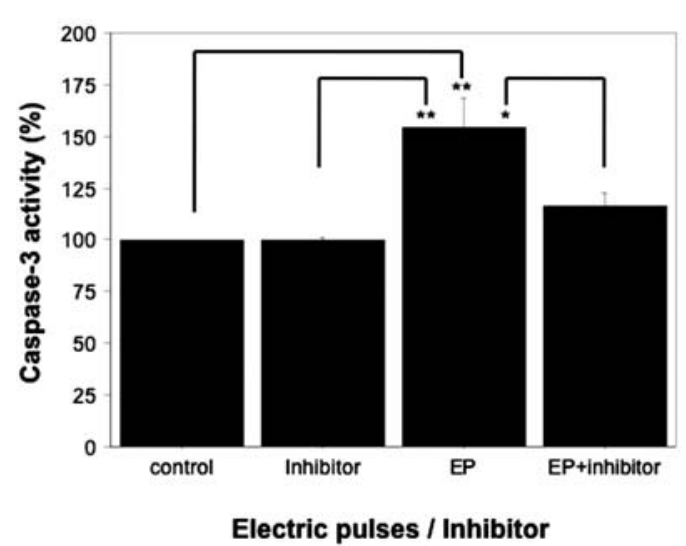

Figure 5. Inhibition of apoptosis and caspase-3 activity by the pan-caspase inhibitor, Z-VAD-FMK. Cells were incubated with Z-VAD-FMK for 1 h before electric exposure. Apoptosis and caspase-3 activity were analyzed via flow cytometry $24 \mathrm{~h}$ after the electric pulse treatment. (A) Flow cytometry plot for annexin V-FITC and 7-AAD staining. (a) Control cells; (b) electric pulse-treated cells; (c) electric pulse + Z-VAD-FMK-treated cells. (B) Apoptosis rate. (C) Caspase- 3 activity. Data are shown as the mean \pm the standard error of the mean of four separate experiments, each performed in duplicate. ${ }^{*} \mathrm{P}<0.05 ;{ }^{* *} \mathrm{P}<0.01$.

with Z-VAD-FMK ( $<<0.05$ vs. electric pulses alone). These results indicated that $73.6 \%$ of apoptotic cells exposed to LVEP were inhibited by Z-VAD-FMK.

Fig. 5C shows caspase-3 activity. The fluorescence intensity of the control cells was regarded as $100 \%$. On average, the $\%$-fluorescence intensity of the cells exposed to electric pulses increased to $154.1 \pm 14.2 \%$ (compared to the control value set at $100 \% ; \mathrm{P}<0.01$ vs. control and inhibitor, $\mathrm{P}<0.05$ vs. electric pulse + inhibitor), whereas $\%$-fluorescence intensity remained at $99.7 \pm 1.1 \%$ for cells incubated with $\mathrm{Z}-\mathrm{VAD}-\mathrm{FMK}(\mathrm{P}<0.01$ vs. electric pulse $)$ and at $114.0 \pm 6.9 \%$ for cells exposed to electric pulses with Z-VAD-FMK $(\mathrm{P}<0.05$ vs. electric pulse). These results indicated that the percentage of cells showing LVEP-induced caspase-3 activation decreased by $74.1 \%$ in response to Z-VAD-FMK treatment. Taken together, these experiments showed that Z-VAD-FMK suppresses LVEP-induced apoptosis by inhibiting caspase-3 activity.

Cell growth. To assess the effect of LVEP stimulation on B16 cell growth, cells exposed to triple square wave pulses at $15 \mathrm{~V}$ $(7.5 \mathrm{~V} / \mathrm{mm})$ for $1000 \mathrm{~ms}$ and control cells were counted at 


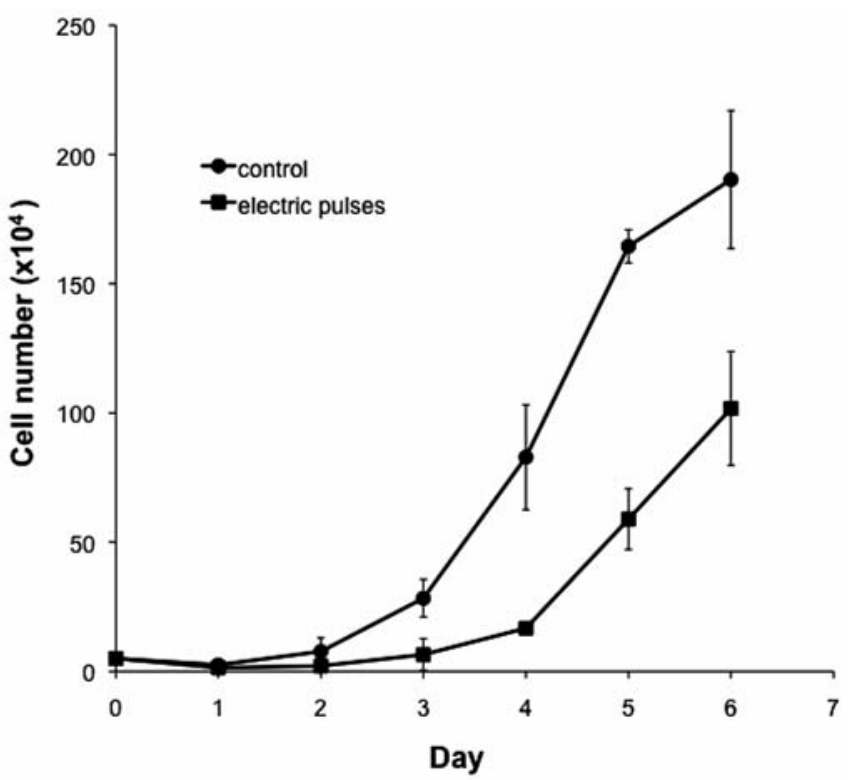

Figure 6. Effect of low-voltage electric pulses on cell growth. Electric pulsetreated cells and control cells ( $5 \times 10^{4}$ cells each) were incubated in RPMI-1640 containing $10 \%$ fetal bovine serum at $37^{\circ} \mathrm{C}$ under $5 \% \mathrm{CO}_{2} / 95 \%$ air. The cells were counted using a cell viability analyzer at 24-h intervals for 6 days. Data are shown as the mean \pm the standard error of the mean of two separate experiments, each performed in triplicate.

24-h intervals over 6 days using a cell viability analyzer. The growth curve illustrated in Fig. 6 indicates that LVEPs inhibit B16 cell growth.

\section{Discussion}

Electroporation induces pore formation and high membrane permeability when the membrane potential of cells rises above the membrane breakdown threshold $(1,4)$. However, when the membrane potential of cells remains below the membrane breakdown threshold, extracellular substance transport occurs via phagocytosis $(13,14)$.

In our experiments, we used $15-\mathrm{V}(7.5 \mathrm{~V} / \mathrm{mm})$ electric pulses for cell stimulation. This voltage was selected because it produces a membrane potential less than half that of the breakdown threshold $(200-250 \mathrm{mV})(1,4)$. Specifically, this value was calculated using the formula $V_{t}=1.5 \times \mathrm{Ex}$ a, where $\mathrm{V}_{\mathrm{t}}$ is the membrane potential, $\mathrm{E}$ is the electrical field and $\mathrm{a}$ is the cell radius for B16 cells (ca. 14-16 $\mu \mathrm{m}$ ) (19). Therefore, we assumed that the observed increase in membrane permeability, as determined by increased PI uptake, was due not to electroporation, but rather phagocytosis under a low-voltage electrical field.

Consistent with previous studies $(20,21)$, PI uptake increased linearly with increased pulse duration and pulse number (Fig. 1). Similarly, the rate of apoptosis increased in accordance with PI uptake, suggesting that the uptake of extracellular substances from the medium may induce apoptosis.

LVEPs were previously reported to induce membrane structural change and vesicle formation and to affect ion transport over the course of several days $(14,22)$. As changes in $\mathrm{K}^{+}$and in particular $\mathrm{Ca}^{2+}$ may induce apoptosis $(11,23,24)$, such ion dysregulation and the influx of extracellular substances is thought to induce apoptosis gradually over an extended period of time. In our experiments, we analyzed caspase- 3 activity as representative of the caspase pathways activated during apoptosis (25-27) and we observed mild but persistent caspase-3 activation over $48 \mathrm{~h}$, a relatively long period (Fig. 4). These data appear to support the idea that membrane dysfunction and LVEP-induced phagocytosis continued over a long period.

Moreover, we used a pan-caspase inhibitor (Z-VAD-FMK) to assess the relative degree of caspase dependency in LVEPinduced apoptosis. Caspase- 3 is a key enzyme in the caspaseinduced apoptotic pathway; it is the main downstream effector caspase that is activated by the initiator caspases, caspase- 8 of the cell death receptor pathway and caspase- 9 of the mitochondrial pathway, leading to the cleavage of a number of cellular substrates leading to apoptosis (25-27). Thus, caspase- 3 activity represents the activation of the greater part of the caspase cascade. In cells exposed to electric pulses, $73.6 \%$ of apoptotic cells were inhibited by the Z-VAD-FMK treatment (Fig. 5B). Note that Z-VAD-FMK also induced cell death, including apoptosis, which is consistent with previous studies $(28,29)$. Accordingly, ZVAD-FMK may cause endoplasmic reticulum (ER) stress and thus induce apoptosis (30-32). Furthermore, $74.1 \%$ of caspase- 3 activity in electric pulse-treated cells was inhibited by the Z-VAD-FMK treatment (Fig. 5C). This finding is also compatible with other studies (33-35). Caspases are roughly divided into initiator caspases and effector caspases (e.g., caspase-3, -6 and -7). Although caspase-3 and -7 are structurally similar and can be inhibited by Z-VAD-FMK, caspase- 6 shows very different characteristics and cannot be inhibited by Z-VAD-FMK (33). In addition, caspase- 6 is activated by both caspase-3-dependent and -independent cascades (36). Moreover, FAM-DEVD-FMK used for measuring caspase-3 activity can also bind to caspase-7 and -6. Thus, Z-VAD-FMK does not completely inhibit effector caspase activity. If LVEP-induced effector caspase activity was completely inhibited, apoptosis would also be expected to be completely abolished. Therefore, persistent apoptosis is likely due to the inadequate inhibition of caspase- $6(25,37)$. Nevertheless, our data indicate that LVEP-induced apoptosis was primarily dependent upon caspase-3 activation.

As shown in Fig. 4B, LVEPs activated both the cell death receptor (caspase-8) and mitochondrial (caspase-9) pathways. Therefore, LVEP stimulation appears to have widespread and non-specific cellular effects, likely involving complex changes to the extracellular environment, membrane structure, ion transport and the transport of vesicles containing various substances, such that LVEPs function as both intrinsic and extrinsic stressors. These various stressors may naturally induce membrane dysfunction, mitochondrial stress, and ER stress, and could activate the caspase pathway (38). Moreover, electric pulse treatment induces intracellular $\mathrm{Ca}^{2+}$ flux $(11,39)$. Accordingly, the primary mechanism underlying apoptosis in response to LVEPs may involve membrane structural change, vesicle formation, and disrupted ion transport, resulting in the influx of $\mathrm{Ca}^{2+}$ and 
extracellular substances that simultaneously activate both the cell death receptor and mitochondrial caspase cascades. Under this assumption, the greater part of LVEP-induced apoptosis is likely dependent upon caspase-3 activation.

Finally, we investigated the effect of LVEPs on cell growth to assess the applicability of this method in anticancer treatment. LVEPs inhibited cell growth by inducing apoptosis, as well as necrosis (Figs. 3A-C and 6). The cell death ratio (apoptosis/total cell death) in response to LVEPs was markedly higher compared to that of control cells (Fig. 3D), suggesting that LVEP stress allowed the selective induction of apoptosis. Notably, long-duration pulses were much more effective in inducing apoptosis, singling out this method as a potential strategy in anticancer treatment.

In summary, LVEPs that induce membrane potentials below the membrane breakdown threshold increase membrane permeability without pore formation through increased extracellular transport via phagocytosis. In addition, LVEPs induce apoptosis in a manner that is primarily, but not wholly, dependent upon caspase-3 activation. LVEP-induced apoptosis may result from membrane dysfunction that disrupts the transport of $\mathrm{Ca}^{2+}$ and extracellular substances, which are potent caspase activators. However, further studies are required to define the electric pulse conditions that most effectively induce apoptosis and to elucidate the detailed mechanism of LVEPinduced apoptosis.

\section{Acknowledgements}

This study was supported by Grants-in-Aid for Scientific Research (C) and (S) from the Japan Society for the Promotion of Science (JSPS; No. 21500402 and No. 19100008). We also acknowledge support from the 2007 Global COE Program of the Global Nano-Biomedical Engineering Education and Research Network Center.

\section{References}

1. Weaver JC: Electroporation of cells and tissues. IEEE T Plasma Sci 28: 24-33, 2000.

2. Rubinsky B: Irreversible electroporationin medicine. Technol Cancer Res 6: 255-259, 2007

3. Sersa G, Miklavcic D, Cemazar M, Rudolf Z, Pucihar G and Snoj M: Electrochemotherapy in treatment. EJSO 34: 232-240, 2007.

4. Teissie J, Golzio M and Rols MP: Mechanism of cell membrane electropermeabilization: a minireview of our present (lack of ?) knowledge. BBA 1724: 270-280, 2005.

5. Hoffmann F, Ohnimus H, Scheller C, Strupp W, Zimmermann U and Jassoy C: Electric field pulses can induce apoptosis. J Membr Biol 169: 103-109, 1999.

6. Hilpert F, Heisert A, Wieckhorst W, Arnold N, Kabelitz D, Jonat W and Pfisterer J: The impact of electricalcharge on the viability and physiology of dendric cells. Scand J Immunol 62: 399-406, 2005

7. Beebe SJ, Fox PM, Rec LJ, Willis LK and Schoenbach KH: Nanosecond, high-intensity pulsed electric fields induce apoptosis in human cells. FASEB J 17: 1493-1495, 2003.

8. Galluzzi L, Maiuri MC, Vitale I, Zischka H, Castedo M, Zitvogel L and Kroemer G: Cell death modalities: classification and pathophysiological implications. Cell Death Differ 14: 1237-1243, 2007.

9. Elmore S: Apoptosis: a review of programmed cell death. Toxicol Pathol 35: 495-516, 2007.

10. Russo A, Terrasi M, Agnese V, Santini D and Bazan V: Apoptosis: a relevant tool for anticancer therapy. Ann Oncol 17 (Suppl 7): vii115-vii123, 2006
11. Tang LL, Sunn CX, Liu H, Mi Y, Yao CG and Li CX: Steep pulsed electric fields modulate cell apoptosis through the change of intracellular calcium concentration. Colloids Surf B Biointerfaces 57: 209-214, 2007.

12. Matsuki N, Ishikawa T, Imai Y and Yamaguchi T: Low voltage pulses can induce apoptosis. Cancer Lett 269: 93-100, 2008.

13. Rosenberg Y and Korenstein R: Incorporation of macromolecules into cells and vesicles by low electric fields: induction of endocytotic-like processes. Bioelectrochem Bioenergetics 42: 275-281, 1997.

14. Antov Y, Barbul A and Korenstein R: Electroendocytosis: stimulation of adsorptive and fluid-phase uptake by pulsed low electric fields. Exp Cell Res 297: 348-362, 2004.

15. Entin I, Plotnikov A, Korenstein R and Keisari Y: Tumor growth retardation, cure, and induction of antitumor immunity in B16 melanoma-bearing mice by low electric field-enhanced chemotherapy. Clin Cancer Res 3190: 3190-3197, 2003.

16. Hock BD, Roberts G, McKenzie JL, Gokhale P, Salm N, McLellan AD, Patton NW and Roake JA: Exposure to the electrofusion process can increase the immunogenicity of human cells. Cancer Immunol Immunother 54: 880-890, 2005.

17. Jiang M, Wang CY, Huang S, Yang T and Dong Z: Cisplatininduced apoptosis in p53-deficient renal cells via the intrinsic mitochondrial pathway. Am J Physiol Renal Physiol 296: 983-993, 2009.

18. Konstantakou EG, Voutsinas GE, Karkoulis PK, Aravantinos G, Margaritis LH and Stravopodis DJ: Human bladder cancer cells undergo cisplatin-induced apoptosis that is associated with p53dependent and p53-independent responses. Int J Oncol 35: 401-416, 2009

19. Pucihar G, Kotnik T, Teissie J and Miklavcic D: Electropermeabilization of dense cell suspensions. Eur Biophys J 36: 173-185, 2007.

20. Rols MP and Teissie J: Electropermeabilization of mammalian cells to macromolecules: control by pulse duration. Biophys J 75: 1415-1423, 1998.

21. Zaharoff DA, Henshaw W, Mossop B and Yuan F: Mechanistic analysis of electroporation-induced cellular uptake of macromolecules. Exp Biol Med 233: 94-105, 2008.

22. Hojman P, Gissel H, Andre FM, Cournil-Henrionnet C, Eriksen J, Gehl J and Mir LM: Physiological effects of high- and lowvoltage pulse combinations forngene electrotransfer in muscle. Hum Gene Ther 19: 1249-1260, 2008.

23. Kim JA, Kang YS and Lee YS: Activation of $\mathrm{Na}^{+}, \mathrm{K}^{+}, \mathrm{Cl}^{-}$ cotransport mediates intracellular $\mathrm{Ca}^{2+}$ increase and apoptois induced by Pinacidil in HepG2 human hepatoblastoma cells. BBRC 281: 511-519, 2001.

24. Vernier PT, Sun Y, Chen MT, Gundersen MA and Craviso GL: Nanosecond electric pulse-induced calcium entry into chromaffin cells. Bioelectrochem 73: 1-4, 2008.

25. Kumar S: Caspase function in programmed cell death. Cell Death Differ 14: 32-43, 2007.

26. Li J and Yuan J: Caspases in apoptosis and beyond. Oncogene 27: 6194-6202, 2008

27. Taylor RC, Cullen SP and Martin SJ: Apoptosis: controlled demolition at the cellular level. Mol Cell Biol 9: 231-241, 2008.

28. Wang GY, Lv QH, Dong Q, Xu RZ and Dong QH: Berbamine induces Fas-mediated apoptosis in human hepatocellular carcinoma HepG2 cells and inhibits its tumor growth in nude mouse. J Asian Nat Prod Res 11: 219-228, 2009.

29. Hermanson D, Addo SN, Bajer AA, Marchant JS, Das SGK, Srinivasan B, Al-Mousa F, Michelangeli F, Thomas DD, LeBien TW and Xing C: Dual mechanism of sHA14-1 in inducing cell death through endoplasmic reticulum and mitochondria. Mol Pharmacol 76: 667-678, 2009.

30. Misaghi S, Korbel GA, Kessler B, Spooner E and Ploegh HL: z-VAD-fmk inhibits peptide: N-glycanase and may result in ER stress. Cell Death Differ 13: 163-165, 2006.

31. Hussain SG and Ramaiah KVA: Endoplasmic reticulum: stress, signaling and apoptosis. Curr Sci 93: 1684-1696, 2007.

32. Heath-Engel HM, Chang NC and Shore GC: The endoplasmic reticulum in apoptosis and autophagy: role of the $\mathrm{Bcl}-2$ protein family. Oncogene 27: 6419-6433, 2008.

33. Yee SB, Baek SJ, Park HT, Jeong SH, Jeong JH, Kim TH, Kim JM, Jeong BK, Park BS, Kwon TK, Yoon II and Yoo YH: z-VAD-fmk, unlike BocD-fmk, does not inhibit caspase-6 acting on 14-3-3 / Bad pathway in apoptosis of p815 mastcytoma cells. Exp Mol Med 38: 634-642, 2006. 
34. Huang J, Wu L, Tashiro S, Onodera S and Ikejima T: The augmentation of TNF-induced cell death in murine L929 fibrosarcoma by the pan-caspase inhibitor z-VAD-fmk through pre-mitochondial and MAPK-dependent pathway. Acta Med Okayama 59: 253-260, 2005.

35. Miura T, Chiba M, Kasai K, Nozaka H, Nakamura T, Shoji T, Kanda T, Ohtake Y and Sato T: Apple procyanidins induce tumor cell apoptosis through mitochondrial pathway activation of caspase-3. Carcinogenesis 29: 585-593, 2008.

36. Wu X, Simone J, Hewgill D, Siegel R, Lipsky P and He L: Measurement of two caspase activities simultaneously in living cells by a novel FRET fluorescent indicator probe. Cytometry A 69A: 477-486, 2006.
37. Liang Y, Yan C and Schor NF: Apoptosis in the absence of caspase 3. Oncogene 20: 6570-6578, 2001.

38. Herr I and Debatin KM: Cellular stress response and apoptosis in cancer therapy. Blood 98: 2603-2614, 2001.

39. Okutsu S, Hatakeyama H, Kanzaki M, Tsubokawa $H$ and Nagatomi R: Electric pulse stimulation induces NMDA glutamate receptor mRNA in NIH3T3 mouse fibroblast. Tohoku J Exp Med 216: 181-187, 2008. 